\title{
Features of the Grinding Technology with the Use of Nanomodified Coolant
}

\author{
Igor I. Artemov $1, \mathrm{a}$, Vladimir D. Krevchik ${ }^{1, \mathrm{~b}}$, Sergey A. Nesterov ${ }^{1, \mathrm{c}^{*}}$, \\ Dmitry A. Akimov ${ }^{1, d}$ and Natalia E. Artemova ${ }^{1, \mathrm{e}}$ \\ ${ }^{1}$ Research Institute for Fundamental and Applied Studies, Penza State University, 40 Krasnaya \\ Street, Penza 440026, Russian Federation \\ aartemov@pnzgu.ru, bphysics@pnzgu.ru, cnesterovs@list.ru, dinfo@zao-pztp.ru, \\ eart.natalia2017@mail.ru
}

\section{Keywords: Engineering and Technology, Cavitation, Nanomodification, Nanoparticles}

\begin{abstract}
The results of the analysis of the possibility of constructing a system for ensuring the quality of mechanical engineering parts by nanomodification of the surface layer are presented. The implementation is considered on the example of grinding technologies with nanomodified lubricating coolant. Mathematical models describing the process of creating conditions for nanomodification of the surface layer and algorithms for practical implementation are presented.
\end{abstract}

\section{Introduction}

Formation of quality characteristics in the surface layers has always been the key problem of the production process during grinding operations. Being the finishing stage of processing, any deviations from the specified characteristics lead to failure of the entire process. Stable quality assurance in grinding operations, especially those of profile and deep types $[1,2]$, requires special attention to the design of operational technology. The paper discusses peculiarities of using coolant modified with various nanoparticles for grinding operations in order to improve quality characteristics of the surface layer by controlling surface defect structure of the material being processed.

\section{Characteristics of Grinding Technology Using Nanomodified Lubricating Coolant}

To control metal surface defect structure in designing machining to ensure the quality of the surface layer is an urgent and non-trivial problem. Nowadays, cavitation technologies for grinding intensification [3] and nanotechnologies to prepare lubricating coolants are widely used [4].

When developing grinding technology using nanomodified coolants, the following essential processing conditions must be satisfied: composition of nanomodified coolant (particle material, particle size, concentration); coolant supply conditions (pressure, flow rate, supply method); workpiece allowances for the grinding operation; processing modes (cutting speed, feed rate, cutting depth); material and type of grinding wheel (there is no available information on this condition yet).

To fulfill the above conditions, it is necessary to solve a number of scientific, engineering, and technological problems listed below.

Selection of Coolant Composition with Nanoadditives. The formation of cavitation bubbles within liquids allows solving a number of technological tasks for grinding, and change the quality of physical and chemical conditions of the coolant, namely: to reduce the cutting forces during processing, which provides for longer life of the wheels and increases the grinding ratio [4]; to improve cooling efficiency of the coolant [5]; to modify physical parameters of workpiece surface taking into account the activation of cavitation processes in the liquid, provided the 
presence of surface sediments in microelements $[3,6,7]$; to fill the arising microcracks in the surface layers of workpieces, thus increasing bearing capacity thereof [6].

Recommendations for using various nanoadditives $[7,8]$ in coolant composition to solve functional technological tasks are summarized in Table 1.

Table 1. Applicability of nanoadditives to the coolant

\begin{tabular}{|c|l|l|}
\hline No. & \multicolumn{1}{|c|}{ Functional technological task } & \multicolumn{1}{|c|}{ Recommended additive } \\
\hline 1 & Reducing the cutting force & $\mathrm{Cu}$ \\
\hline 2 & Improving cooling efficiency & $\mathrm{CuO}, \mathrm{NiO}, \mathrm{CNT}$ and $\mathrm{SiC}$ \\
\hline 3 & $\begin{array}{l}\text { Improving the efficiency of lubrication } \\
\mathrm{TiO}_{2}, \mathrm{SiO}_{2}, \mathrm{Al}_{2} \mathrm{O}_{3}, \mathrm{MoS}_{2}, \\
\mathrm{ZnO} \text { and nanodiamond }\end{array}$ \\
\hline 4 & $\begin{array}{l}\text { Modifying surface physical parameters taking } \\
\text { into account the activation of cavitation processes }\end{array}$ & $\mathrm{Ni}, \mathrm{Cu}$ \\
\hline 5 & Filling arising microcracks in the surface layers & $\mathrm{Cu}$ \\
\hline
\end{tabular}

Selection of Filler Composition in the Form of Nanodispersed Powder Additives is based on the adhesive properties of materials. There are practical recommendations on using nanopowder additives in coolant during processing with selection of material type in accordance with the grade being processed $[5,6]$.

For example, when grinding ferritic materials based on zinc manganese or copper compositions, there are recommendations [6] on the introduction of copper nanoparticles into coolant composition. Copper is chosen as a nanopowder material for grinding ferrite alloys due to the absence of influence of particles integrated into surface microcracks on the magnetic properties of materials. Besides, being filler in the coolant, copper is a versatile material, since it has high adhesion and penetrating properties to most metal materials processed by grinding. When grinding nickel-based superalloys, it is strongly recommended [6] to use nickel nanopowders as fillers.

Selection of Filler Particle Size in the Form of Nanodispersed Powder Additives is based on the key task to obtain penetration of particles into the deformed surface layer resulting from grinding. To accomplish this, one has to estimate the sizes of pores and microcracks on the surface, and select a particle size by three orders of magnitude smaller. For example, in [8], sizes of microcracks in ferrites are studied after being processed with diamond grinding wheels, and the crack width being 0.1-0.3 $\mathrm{mm}$. In accordance with these data, it is recommended to use copper nanopowders with 50-100 nm particle size as additives. Damages to the surface layers in the form of microcracks with a width of 0.01-0.02 $\mathrm{mm}$ [9] were found during deep grinding of turbine blades made of superalloy. In accordance with [6], it is advisable to use nickel powders with 7-80 nm particle size.

Selection of Grinding Modes is based on the calculations recommended by the reference books, and theoretical calculation of the operating conditions of cavitation processes occurring in the nanomodified coolant.

During finishing processing by grinding with the use of nanomodified coolant, the surface of the processed material is actively saturated with nanoparticles from the liquid medium by means of the cavitation mechanism of the acoustocapillary effect with the use of metal nanoparticles contained as additives in the process liquid. 
Cavitation can be realized in a coolant environment due to shock interaction of abrasive grains with the processed surface. The waves propagate through the abrasive grains, and then are transferred to the liquid. The collapse of cavitation bubbles near the surface layer leads to the formation of cumulative jets, which stimulate the penetration of process liquid with nanoparticles into the channels of microcracks. As a result, microcracks of the metal surface layer are filled with nanoparticles, and the effective surface Young's modulus is modified $[10,11,12]$. The use of nano-modified coolant in combination with cavitation processes could form the basis for a strengthening technology to form wear-resistant surface layers. To calculate the collapse time $t_{\mathrm{c}}$ of cavitation bubble, the Nolting-Nepayres equation was used. An analytical formula for $t_{\mathrm{c}}$ was obtained for incompressible liquid approximation when neglecting viscous losses:

$$
t_{c}=\frac{1}{\omega} \arcsin \left[\frac{\omega_{0}^{2} R_{0}^{2} \rho_{0}}{p_{m}} \sqrt{\left(1-\Omega^{2}\right)^{2}+(\delta \cdot \Omega)^{2}}+\sin \varphi\right]-\frac{\varphi}{\omega},
$$

where $\rho_{0}$ is the density of the liquid; $p_{\mathrm{m}}$ is the amplitude of pressure fluctuations in the liquid; $R_{0}$ is the bubble radius; $\omega$ is the vibration frequency; $\omega_{0}$ is the resonant frequency,

$$
\begin{aligned}
& \omega_{0}=\frac{1}{2 \pi R_{0}} \sqrt{\frac{3 \gamma p_{0}}{\rho_{0}}} ; p_{0} \text { is the atmospheric pressure; } \Omega=\omega^{\prime} / \omega_{0} ; \delta \text { is the logarithmic decrement; } \\
& \operatorname{tg} \varphi=-\delta \cdot \Omega /\left(1-\Omega^{2}\right) .
\end{aligned}
$$

The value of $t_{\mathrm{c}}\left(10^{-8} \mathrm{~s}\right)$ has been estimated for the following parameters from Eq. (1) $\left(R_{0}=10^{-6}\right.$ $\mathrm{m}, p_{0}=10^{5} \mathrm{~Pa}, \rho_{0}=103 \mathrm{~kg} / \mathrm{m}^{3}, \gamma=1.4$, and $\left.\delta=0.10\right)$, constrained by:

$$
\left|\frac{\omega_{0}^{2} R_{0}^{2} \rho_{0} \delta}{p_{m}} \Omega+\sin \varphi\right| \leq 1 .
$$

It can be seen that $t_{\mathrm{c}}$ depends on the vibration frequency, the bubble radius, coolant density, amplitude of pressure fluctuation in the liquid, and on the logarithmic decrement.

The $t_{\mathrm{c}}$ value is bounded from above: $\omega t_{\mathrm{c}}<1$, where $\omega$ is the vibration frequency. The cavitation bubble should collapse in a time shorter than the vibration period.

Let us analyze the potential of cavitation bubbles during grinding with wheels, taking into account the distribution of grains [13] in the structure of the wheel. Cavitation penetration of microparticles from the collapsing bubble into the formed crack occurs on the surface of the processed material at the moment of interaction between the grain and the formed microcrack. The vibration frequency should be calculated based on the distance parameters between the abrasive grains and the peripheral speed of the abrasive wheel.

The average distance between the abrasive grains for the wheels of the main grain fraction and structure can be calculated as:

$$
l=\sqrt[3]{\frac{1000}{g \cdot n}}=\sqrt[3]{\frac{1000000}{(62-2) \cdot N \cdot \gamma \cdot n}},
$$


where $\gamma$ is specific gravity of the abrasive material determined experimentally [14], being $\gamma=3.85$ for aluminium oxide and $\gamma=3.10 \ldots 3.20$ for silicon carbide; $N$ is the structure number of the grinding wheel; $g$ is the weight of abrasive grains in $1 \mathrm{~cm}^{3}$ of the wheel determined as $g=(62$ $2 \cdot N) \cdot \gamma / 100 ; n$ is the amount of grains in $1 \mathrm{~g}$ of grain (the $n$ value is not stable, being 3,000 for 60grit aluminium oxide grinding wheel [13]).

According to Eq. 3, the calculated average distance between the abrasive grains is $0.252 \mathrm{~mm}$ for the wheels of 60-grit and No. 4 structure.

The vibration frequency can be estimated by the classical formula $\omega=V_{K} / 1$ during the grain passage over the processed surface.

Taking into account the real speed of the grinding wheel $V_{\kappa}$ of $35 \mathrm{~m} / \mathrm{s}$, we obtain the vibration frequency $\omega$ from $71 \mathrm{kHz}$ to $146 \mathrm{kHz}$. Based on the condition for bubble collapse time $t_{c}\left(\omega t_{c}\right.$ $<1$ ), it can be estimated that the calculated vibration frequencies match the limit parameters.

The performed estimation of the amount of nanoparticles $N_{H}$ found in the microcrack has shown its dependence on the time of cavitation bubble collapse and geometric parameters of the microcrack. An analytical formula [15] for the effective Young's modulus of the metal surface layer has been obtained:

$$
\frac{E_{\text {eff }}}{E_{1}}=\frac{4 r_{H}^{3}}{r_{0}^{2} L_{M C}} \cdot N_{H} \cdot\left(1-\frac{16 u_{0}}{\pi N_{M C}}\right)+\frac{16 u_{0}}{\pi N_{M C}},
$$

where $r_{0}$ is the radius of the microcrack base (the geometric shape of a microcrack is modeled by a cone with a height $L_{\mathrm{Mc}}$, and the base radius $\left.r_{0}\right) ; E_{1}$ is the Young's modulus in the volume of the structural material; $u_{0}$ is the distance dispersion between microcracks; $N_{\mathrm{Mc}}$ is the amount of microcracks on the metal surface.

It is observed that the effective Young's modulus is a function of the number of nanoparticles found in the microcrack channel, and the size of nanoparticles and microcracks. The performed assessment has shown that the effective Young's modulus can exceed its initial value by about an order depending on the time of cavitation bubble collapse.

Thus, by varying $t_{\mathrm{c}}$, it is possible to control such metal surface characteristics as roughness (due to pore and microcavity filling with metal nanoparticles), and microhardness (due to the change in the effective Young's modulus).

To test the method for selection of coolant composition, we consider the processing technology using an installation for coolant aeration (Fig. 1). Aeration of liquid is achieved by high-speed radial jets of compressed air throughout the entire volume of the liquid flow. Then the liquid is fed into device 8 for mixing it with hard-facing metal (nickel) nanopowder with a size of 7-80 nm. 


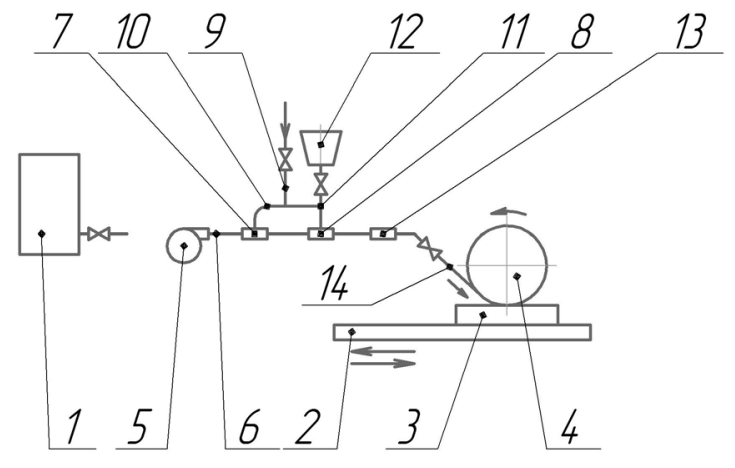

a)

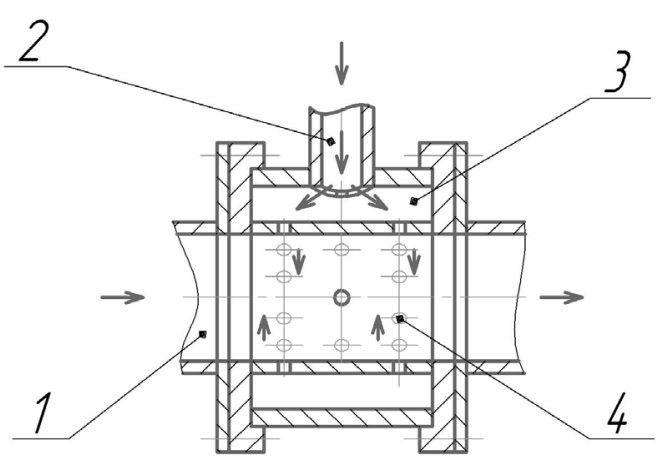

b)

Fig. 1. An installation for coolant aeration: a) overall scheme (1-lubricating coolant tank; 2

- grinding machine table; 3 - workpiece; 4 - abrasive tool, 5 - pump; 6 - lubricating

coolant supply pipeline; 7- aerator; 8 - liquid and nanopowder mixing device; 9 - compressed air supply pipeline; 10,11 - air exhaust pipes; 12 - nanopowder container; 13 - hydrodynamic cavitation device for liquid flow treatment; 14 - coolant supply pipeline); b) aeration zone(1liquid supply pipeline; 2 - compressed air supply pipe; 3 - annular chamber for compressed air spraying; 4 - radial air outlets).

In device 8 , the liquid is turbulized due to tangential air jet. Further, the aerated and turbulized fluid flow with nanopowder nanoparticles, uniformly distributed in the liquid medium, is fed to device 13 for hydrodynamic cavitation processing of liquid flow to form cavitation bubbles in the liquid and increase their total volume in the liquid to 45-60 vol. \%. Nanoparticles of hard-facing metal (nickel) are concentrated along the boundaries of cavitation bubbles. The liquid saturated with cavitation bubbles and nanoparticles enters receiver 2, and its velocity and turbulence being decreased. Having been processed, the lubricating coolant is fed into the grinding area through pipeline 14 via the coolant supply system of the machine-tool. The implantation of hard-facing metal nanoparticles into microcracks and dislocations of the part surface is performed simultaneously with grinding [6].

\section{Implementation of the Technology Design Concept}

An algorithm for the RTP 2000 system procedure of computer-aided design of technological processes has been applied for grinding operation synthesis. The system has been developed at Penza State University (Penza, Russia) since the 2000s [16], and operates according to the principle described in [17]. An open architecture of this system allows users to independently implement their algorithms therein.

An example of grinding operational technology implementation in accordance with Russian standards for technology description is shown in Fig. 2. The example is given in Russian, since the software product is adapted to the Russian system of technological document management. Fig. 2 presents input box entries for the key parameters of a technological operation. 


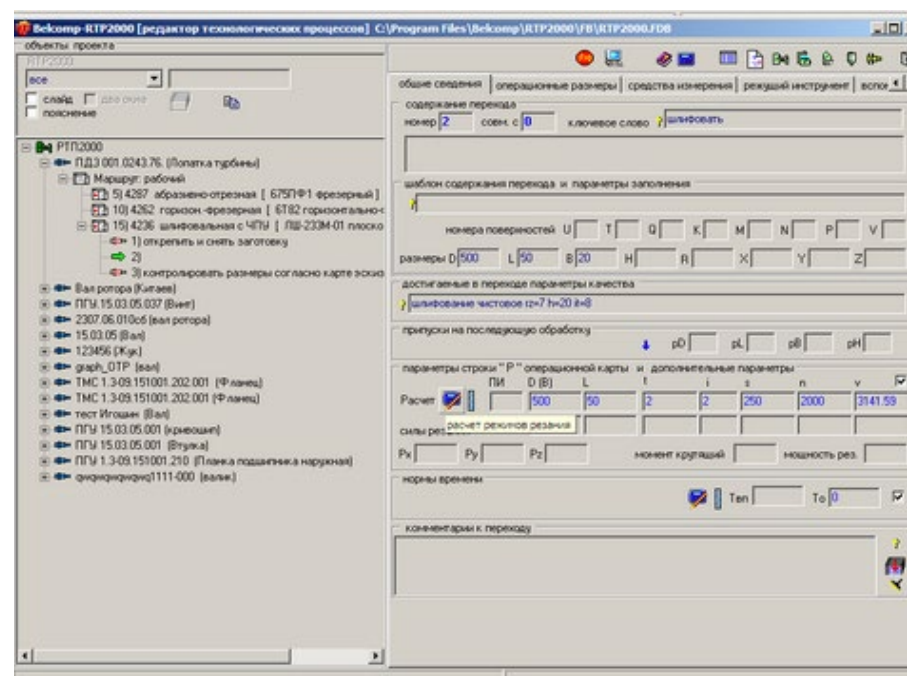

Fig. 2. Input box entries for the key parameters of a technological operation.

The software comprises the algorithms described above. There is an algorithm to select parameters and processing conditions in the system with built-in model. It allows to recommend a user the formation of an operational technology by creating the most adequate composition of the operation. Having analyzed the proposed option, the user is able to edit the content of operational transitions. The system gains new knowledge after user's edition, and considers the best algorithms to form the content and conditions for the considered data implementation in future.

\section{Summary}

Mathematical models for nanocluster formation mechanism have been created in the volume of metal surface layer microstructure under the conditions of its cavitation processing with a nanomodified lubricating coolant.

Methods and recommendations for regulating technological modes of finishing metal parts and assemblies with a nanomodified coolant under cavitation have been developed.

To create a technological system, a methodology and an algorithm for controlling a technological process to ensure quality of finishing metal products with a nanomodified lubricating coolant under cavitation have been developed and introduced into the RTP 2000 system of computer-aided design of technological processes.

\section{Acknowledgements}

The present study was supported by the Ministry of Education and Science of the Russian Federation (Project \# 0748-2020-0012).

\section{References}

[1] G.A. Kardashev, Physical Methods for Intensification of Chemical Technology Processes, Chemistry Publishing, Moscow, 1990.

[2] S.S. Silin, B.N. Leonov, V.A. Khrulkov, V.A. Poletaev, A.V. Lobanov and N.S. Rykunov, Optimization of Creep-Feed Grinding Technology, Mechanical Engineering Publishing House, Moscow, 1989.

[3] M.A. Promtov, Prospects of cavitation technologies application for intensification of chemical technological processes, TSTU Transactions 14 (2008) 861-869. 
[4] B. Shen, P. Kalita, A. Malshe and A. Shih, Performance of novel MoS2 nanoparticles based grinding fluids in minimum quantity lubrication grinding. Transactions of NAMRI/SME 36 (2008) 357-364.

[5] M. Yang, Ch. Li, Y. Zhang, D. Jia, R. Li and W. Ding, Thermodynamic mechanism of nanofluid minimum quantity lubrication cooling grinding and temperature field models, in: M.Sh. Kandelousi (Ed.), Microfluidics and Nanofluidics, IntechOpen Ltd., London, 2018. https://doi.org/10.5772/intechopen.74969

[6] I.I. Artemov, E.M. Kirin, V.D. Krevchik and N.P. Simonov, Method of hard facing of metal part, RU Patent 2560604 C1 (2015).

[7] F. Pashmforoush, R.D. Bagherinia, Influence of water-based copper nanofluid on wheel loading and surface roughness during grinding of Inconel 738 superalloy, J. Clean.

Prod. 178 (2018) 363-372. https://doi.org/10.1016/j.jclepro.2018.01.003

[8] V.D. Krevchik, V.O. Sokolov and D.V. Vasin, Acoustically stimulated change in physical and mechanical properties of the surface layer of ferrite products, in: Proceedings of All-Russian Scientific and Technical Conference on Improving Efficiency of Machining Based on Modeling Physical Phenomena, RSATU, Rybinsk, 2009.

[9] A.P. Zhuk, V.A. Skryabin and A.G. Skhirtladze, Features of processing technologies for blade root of diesel turbochargers, Repair, Reconditioning, Modernization 11 (2012) 30-33.

[10] I.I. Artemov, V.D. Krevchik, Acoustic emission under "hidden" growth of microcracks, J. Mach. Manuf. Reliab. 4 (2005) 92-95.

[11] I.I. Artyomov, V.D. Krevchik and N.P. Simonov, The quantum nanocluster formation mechanism in the surface layer of a metal with the chain of microcracks in terms of acoustocapillary effect cavitation mode, University proceedings. Volga region. Technical sciences 4 (2011) 192-204.

[12] I.I. Artemov, V.D. Krevchik, A.V. Rudin, N.E. Artemova, A.A. Voinov, S.B. Menshova, A.V. Sokolov, N.P. Simonov and A.V. Lipov, Method to produce nanostructured layer on surface of metals under conditions of acoustocapillary effect, RU Patent 2547051 C2 (2015).

[13] P.I. Yashcheritsyn, A.G. Zaitsev, Improving the Quality of Ground Surfaces and Cutting Properties of Abrasive Diamond Tools, Science and Technology Publishing House, Minsk, 1972.

[14] E.N. Maslov, Basics of Metal Grinding Theory, Mashgiz Publishing House, Moscow, 1951.

[15] I.I. Artemov, V.D. Krevchik, N.P. Simonov and R.V. Zaytsev, Application of cavitation technologies and nano-modifiers of the process fluid in the surface engineering of machine parts, in: Proceedings of International Conference on Surface Engineering for Research and Industrial Applications (INTERFINISH-SERIA 2014), Novosibirsk, Russia, 30 June-04 July 2014, pp. 4344.

[16] V.A. Belashov, A.V. Belashov and M.V. Belashov, Technological process editor, Certificate 940187 of Russian Agency for the Protection of Computer Programs, Databases and Topologies of Integrated Circuits (1994).

[17] V.A. Belashov, A.V. Belashov and M.V. Belashov, Operation technology synthesis automation based on the dimensional analysis, University proceedings. Volga region. Technical sciences, 2 (2007) 100-108. 